Check for updates

Cite this: RSC Adv., 2018, 8, 38131

Received 24th September 2018 Accepted 4th November 2018

DOI: $10.1039 / \mathrm{c} 8 \mathrm{ra0} 07930 \mathrm{~g}$

rsc.li/rsc-advances

\section{Extraction and isolation of polyhydroxy triterpenoids from Rosa laevigata Michx. fruit with anti-acetylcholinesterase and neuroprotection properties $\dagger$}

\author{
Pinyi Gao, (D) ab Ting Han, ${ }^{a}$ Mei Jin, ${ }^{a}$ Danqi Li, ${ }^{b}$ Fuyu Jiang, ${ }^{a}$ Lixin Zhang*b \\ and Xuegui Liu ${ }^{\star a b}$
}

Rosa laevigata fruit, at present, is becoming increasingly popular as a functional foodstuff with several nutritional and medicinal properties. To explore the acetylcholinesterase (AChE) inhibitory activity of extracts from the Rosa laevigata Michx. fruit (RLMF), a simple and efficient enrichment purification technology based on microwave-assisted extraction (MAE) and multi vacuum extraction columns (VEC) was applied to screen and identify triterpenoids (TTS) in the RLMF extracts. The MAE conditions were optimized using the Box-Behnken design (BBD) with a quadratic regression model and the response surface method (RSM). The optimum conditions were as follows: ethanol concentration, 69\%; extraction time, $12 \mathrm{~min}$; ratio of liquid to raw material, $26: 1 \mathrm{~mL} \mathrm{~g}^{-1}$; and microwave power, $528 \mathrm{~W}$. Under these conditions, the maximum content of triterpenoids reached $62.48 \pm 0.25 \mathrm{mg} \mathrm{g}^{-1}$, which was close to the predicted value of $62.69 \mathrm{mg} \mathrm{g}^{-1}$. In addition, two pure polyhydroxy triterpenoids: $2 \alpha, 3 \beta, 19 \alpha, 23$ tetrahydroxyurs-12-en-28-oic acid (1) and 2 $\alpha, 3 \beta, 19 \alpha, 23$-tetrahydroxyurs-12-en-28-oic acid-28-O- $\beta$-Dglucopyrannoside (2) were isolated and enriched to more than $500 \mathrm{mg}$ by a multi VEC method. Furthermore, the quantities of compounds 1 and 2 from RLMF were 5.36 and $10.37 \mathrm{mg} \mathrm{g}^{-1}$, respectively, as determined using HPLC. These compounds were further assessed for acetylcholinesterase inhibitory and neuroprotection properties. The results showed that 1 and 2 showed potent AChE inhibitory activities with $\mathrm{IC}_{50}$ values of 29.22 and $45.47 \mu \mathrm{g} \mathrm{mL} \mathrm{L}^{-1}$, respectively. At high concentration, compounds 1 and 2 produced a $92 \%$ and $89 \%$ inhibition on the target enzyme, which was consistent with docking results between $\mathrm{AChE}$ and each isolate. Moreover, both 1 and 2 exhibited potential neuroprotective activities against $\mathrm{H}_{2} \mathrm{O}_{2}$-induced $\mathrm{SHSY} 5 Y$ cell death.

\section{Introduction}

During the recent three decades, the population of China has been steadily increasing, with over 200 million Chinese adults aged 60 years and above, accounting for more than $15 \%$ of the total population. ${ }^{\mathbf{1}}$ Accordingly, the incidence of Alzheimer's disease $(\mathrm{AD})$ in elderly people is on the rise. Consequently, there has been increasing interest in exploring alternative treatments for AD. Some drugs, especially AChE inhibitors, have been suggested and even applied in the treatment of AD symptoms. ${ }^{2}$ Physostigmine and galanthamine, along with other natural

${ }^{a}$ College of Pharmaceutical and Biotechnology Engineering, Shenyang University of Chemical Technology, Shenyang 110142, People's Republic of China. E-mail: gpy1981@163.com; liuxuegui72@163.com

${ }^{b}$ Institute of Functional Molecules, Shenyang University of Chemical Technology, Shenyang 110142, China

$\dagger$ Electronic supplementary information (ESI) available. See DOI: 10.1039/c8ra07930g alkaloids and herbal drugs, have been demonstrated to possess significant therapeutic effects for $\mathrm{AD}^{3}$

Rosa laevigata Michx., belongs to the Rosaceae family of the evergreen climbing plant and is a traditional folk herb widely used in China. ${ }^{4}$ In the Chinese Pharmacopoeia, its fruits are widely recommended to treat urinary incontinence, urinary frequency, paregoric menstrual irregularities, uterine prolapse, leucorrhea and astringency. ${ }^{5,6}$ Moreover, Rosa laevigata Michx. fruits can also be used as a health food and food additive, such as a nourishing oral liquid, fruit wine, vinegar, fruit juice and jam. In addition, fruits from this medicinal plant were shown to contain triterpenoids, polysaccharides, flavonoids, organic acid, tannins and other compounds. ${ }^{7}$ The triterpenoids are the main active components of this plant and are particularly valuable as they possess anti-HIV and anti-tumor effects. ${ }^{8}$ The increasing interest in the chemical components of RLMF has arisen from need to identify new potential therapeutic agents, such as sapogenins. The conventional methods used to extract triterpenoids, such as boiling, refluxing and heating, are time- 
consuming, and requires large volumes of solvent and high extraction temperatures and the yields are low. In recent years, a new extraction technique named microwave-assisted extraction (MAE) has been developed and is now widely applied in the extraction of bioactive substances due to its many advantages., ${ }^{9,10}$ Compared with traditional extraction methods, MAE requires less solvent, shorter extraction duration and offers a higher extraction yield. ${ }^{11}$ Hence, to obtain a significant amount of TTSs from RLMF, MAE is now considered the method of choice. At the same time, to achieve the maximum extraction yield, the interactive investigation of various extraction factors is performed using response surface methodology (RSM). ${ }^{12}$ Vacuum extraction columns (VEC) are used to prepare the trace pure sample before HPLC. In our previous work, due to the rapidity and robustness of the method, the VEC was also performed during the isolation and enrichment of the principal constituents of the natural plant in our lab. Besides the silica gel VEC and reversed-phase $\mathrm{C}_{18}$ silica gel VEC, polyamide VEC and D101 macroporous resin VEC were also employed for the separation and purification. For the first time, application of the multi-VECs method coupled with MAE process, provided a rapid and efficient enrichment purification technology to obtain and enrich pure polyhydroxy triterpenoids from the extracts of RLMF.

This aim of this study was to optimize MAE process of extracts TTSs from RLMF by RSM and to investigate the antiacetylcholinesterase and neuroprotection properties of compounds 1 and 2. Firstly, single-factor experiments were carried out to determine the ranges of different conditions of MAE. Secondly, the MAE process was optimized by RSM. Thirdly, two major polyhydroxy triterpenoids identified as $2 \alpha, 3 \beta, 19 \alpha, 23$-tetrahydroxyurs-12-en-28-oic acid (1) and $2 \alpha, 3 \beta, 19 \alpha, 23$-tetrahydroxyurs-12-en-28-oic acid-28-O- $\beta$-D-glucopyrannoside (2) were separated and purified with multi-VECs, and their purity and content were examined by HPLC analysis. RLMF has been previously found to inhibit acetylcholinesterase. ${ }^{13}$ Here, in vitro AChE inhibitory assay and AChE molecular docking studies of compounds $\mathbf{1}$ and $\mathbf{2}$ were performed simultaneously. Finally, the $\mathrm{H}_{2} \mathrm{O}_{2}$-induced SH-SY5Y cell death model was used to test the activities of compounds $\mathbf{1}$ and 2 , which indicated that the natural product exhibited protective effects against $\mathrm{H}_{2} \mathrm{O}_{2}$-induced injury in human umbilical vein endothelial cells.

\section{Materials and methods}

\subsection{General methods}

Extraction is carried out using microwave instrument (Xinyi, China). LC3000 HPLC with UV spectrometer was obtained from TengHong, Beijing, China. Microplate system was acquired from iMark, Japan. NMR spectra of each sample were obtained on spectrometer (AVANCE-600, Bruker Inc., Germany). Macroporous resin (D101) was obtained from Ruida henghui, Beijing, China. Silica gel and polyamide were purchased from Xiya Chemical Industry, Shandong, China. Octadecylsilanized silica gel (ODS) were from Merck, Germany. 5,5'-Dithiobis-(2- nitrobenzoic acid) (DTNB), galanthamine hydrobromide, acetylthiocholine (ATCI) and AChE were gained from MAYA-R, China.

\subsection{Plant materials}

Rosa laevigata Michx. fruits (RLMF) were obtained from Nanning, Guangxi province of China, in October 2016. The specimen (RLSY1609) was stored in the Chemical Technology University, Shenyang, China.

\subsection{Extraction of TTSs from RLMF}

MAE was performed in a microwave bath which allowed variations in the duration of treatment and the irradiation power. For the MAE experiments, one gram of pretreated sample was used for each single extraction and a series of different ethanol concentrations (40-80\%), extraction times (4-12 $\mathrm{min}$ ), ratio of liquid to raw material $\left(10-30 \mathrm{~mL} \mathrm{~g}^{-1}\right)$ and microwave power (200-600 W). When the extraction was completed, the extracts were centrifuged at $4000 \mathrm{rpm}$ for $20 \mathrm{~min}$ to collect the supernatants. The filtrates were diluted with water to $100 \mathrm{~mL}$ and $0.1 \mathrm{~mL}$ samples were dried in $80^{\circ} \mathrm{C}$. Accurate measurement of the samples was carried out as described above and a standard curve of saponin was constructed. Using the standard curve constructed from the saponin concentration of the samples and the absorbance of the standard curve regression equation, the content of TTSs $\left(\mathrm{mg} \mathrm{g}^{-1}\right)$ was calculated as follows:

$$
\text { TTSs content }\left(\mathrm{mg} \mathrm{g}^{-1}\right)=(C \times V \times N \times 1000) / W
$$

where $C$ is the saponin concentration measured $\left(\mu \mathrm{g} \mathrm{mL} L^{-1}\right) ; V$ is the volume of the extract (mL); $N$ is the dilution factor; and $W$ is the powder of RLMF $(\mathrm{g})$.

\subsection{Experimental design and statistical analysis}

The optimization of extraction conditions were carried out via RSM. The effects of the extraction conditions, such as the ethanol concentration $\left(X_{1}\right)$, extraction time $\left(X_{2}\right)$, ratio of liquid to raw material $\left(X_{3}\right)$ and microwave power $\left(X_{4}\right)$, for the extraction content of TTSs, were investigated by the single factor experiments. According to single-factor testing results, preliminary ranges of each factor were used for the subsequent experiment design. Moreover, a four-variable, three-level Box-Behnken design (BBD) was employed in the optimization, as shown in Table S2. $\dagger$ Four independent variables $\left(X_{1}-X_{4}\right)$ were studied under three-level.

The coded values of the extraction factors were calculated via following equation:

$$
X_{i}=\left(x_{i}-x_{0}\right) / \Delta x
$$

$X_{i}, x_{i}, x_{0}$ and $\Delta x$ are the variable coded value, the actual value, the independent variable actual value at the center point and the variable change.

As shown in Table 1, a matrix consisting of 29 experimental runs was constructed in random order. According to the 
Table 1 Response surface BBD (coded) and results for extraction content of TTSs

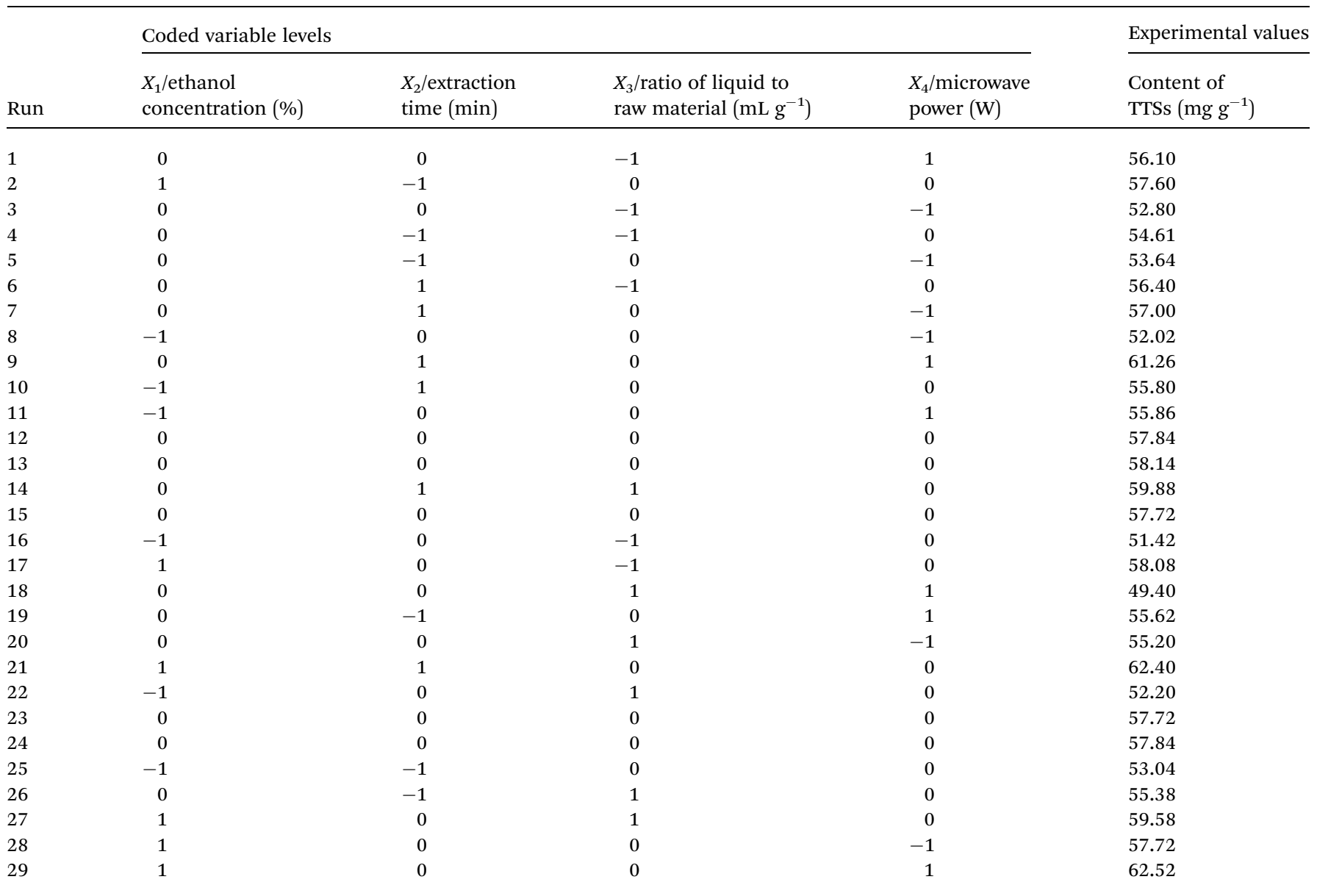

experiment results, the multiple regression quadratic model used in the second-order polynomial formula is given as:

$$
Y=\beta_{0}+\sum \beta_{i} x_{i}+\sum \beta_{i} x_{i}^{2}+\sum \beta_{i j} x_{i} x_{j}
$$

$Y:$ the predicted response, $\beta_{0}$ : the intercept regression coefficient, $\beta_{i}:$ the linear regression coefficient, $\beta_{j}$ : the quadratic regression coefficient and $\beta_{i j}$ : the interaction terms regression coefficients. $x_{i}$ and $x_{j}$ are the independent variables.

The Design-Expert 8.0.6 software was used to design the experimental conditions and statistical analysis of the predicted data. In the regression equations, the statistical significance of the terms was examined by ANOVA for every response. The evaluated adjusted- $R^{2}$ and $R^{2}$ were used to verify the suitability of the model. Subsequently, to prove the reliability of statistical experimental design, three additional confirmation experimental runs were carried out under the optimized conditions which gave a maximum analytical response.

\subsection{Enrichment and separation of triterpenoids with multi vacuum extraction column chromatography (VEC)}

Dried $R$. laevigata fruit powder $(2 \mathrm{~kg})$ was extracted at the following optimal conditions by the RSM: $X_{1}: 69 \%, X_{2}: 12 \mathrm{~min}$, $X_{3}: 26: 1 \mathrm{~mL} \mathrm{~g}^{-1}$ and $X_{4}: 528 \mathrm{~W}$. After they were concentrated in vacuo, a reddish-brown extract (252 g, 12.6\%) was obtained which was dissolved in $5 \mathrm{~L}$ of water and then fractionated by dichloromethane $\left(\mathrm{CH}_{2} \mathrm{Cl}_{2}\right)(5 \mathrm{~L} \times 3)$, to obtain $\mathrm{CH}_{2} \mathrm{Cl}_{2}$ fractions $(25 \mathrm{~g}, 1.3 \%)$. After the removal of the reddish-brown pigment by polyamide $(500 \mathrm{~g}) \mathrm{VEC}$, the $\mathrm{CH}_{2} \mathrm{Cl}_{2}$-soluble extract $(15 \mathrm{~g})$ was subjected to purification on the silica gel $(120 \mathrm{~g})$ VEC using $\mathrm{CH}_{2} \mathrm{Cl}_{2}-\mathrm{MeOH}(100: 1 \rightarrow 5: 1)$ solvent to form fractions E1-E7, from which Fr. E2 (3000 mg) was purified by ODS (50 g) VEC using $\mathrm{MeOH} / \mathrm{H}_{2} \mathrm{O}(50: 50 \rightarrow 90: 10)$. E2-3 was further purified by recrystallization to produce compound $1(520 \mathrm{mg} ; 0.26 \mathrm{mg}$ $\left.\mathrm{g}^{-1}\right)$. The remaining aqueous extract (200 g) was separated by macroporous resin (D101 $3 \mathrm{~kg})$ VEC with $\mathrm{EtOH} / \mathrm{H}_{2} \mathrm{O}(\mathrm{v} / \mathrm{v}=$ $0: 100,10: 90,50: 50,95: 5)$. The $50 \%$ ethanol fraction $(53 \mathrm{~g})$ was further separated by polyamide $(1000 \mathrm{~g}) \mathrm{VEC}\left(\mathrm{EtOH} / \mathrm{H}_{2} \mathrm{O}\right.$ $20: 70,40: 60,60: 40,95: 5$ ) to produce 4 fractions (Frs A3-1 $\rightarrow$ A3-4). A3-3 was further purified by recrystallization to yield compounds 2 (910 mg; $0.455 \mathrm{mg} \mathrm{g}^{-1}$ ) (Fig. 2).

\subsection{HPLC analysis}

Compounds 1 and 2 were determined by HPLC with a UV detector at $210 \mathrm{~nm}$ via a promosil $\mathrm{C}_{18}$ column $(5 \mu \mathrm{m}, 250 \mathrm{~mm} \times$ $4.6 \mathrm{~mm}$ ). The mobile phases were consisted of methanol and water $(48: 52, \mathrm{v} / \mathrm{v})$. The HPLC conditions were set as flow rate of




Fig. S3.1, $\dagger$ chromatograms of triterpenoids extracted from $R$. laevigata were obtained by HPLC analysis according to above conditions. All samples were determined in triplicate.

\subsection{AChE inhibitory assay}

Using an Ellman assay, ${ }^{14} 20 \mu \mathrm{L}$ compounds 1 and $2(2,10,30,60$, $\left.100,150,200 \mu \mathrm{g} \mathrm{mL}^{-1}\right), 140 \mu \mathrm{L}$ phosphate buffer (0.1 M, pH 7.4) and $15 \mu \mathrm{L}$ acetylcholinesterase $\left(0.4 \mathrm{U} \mathrm{mL}^{-1}\right)$ were maintained in the each of 96-microtiter well plates for $20 \mathrm{~min}$ at $4{ }^{\circ} \mathrm{C}$. Next, 10 $\mu \mathrm{L}$ ATCI and $20 \mu \mathrm{L}$ DTNB were added, maintained for $30 \mathrm{~min}$ at $37{ }^{\circ} \mathrm{C}$. The absorbance was detected at $405 \mathrm{~nm}$ via a microplate apparatus. A positive control was carried out using galanthamine. Then, all tests were carried out in triplicate. SPSS statistical software was carried out to calculate the $\mathrm{IC}_{50}$ values. The inhibition rate (\%) was calculated by the following formula:

Inhibitory rate $(\%)=\left[\left(A_{0}-A_{\mathrm{c}}\right)-\left(A_{\mathrm{s}}-A_{\mathrm{b}}\right)\right] /\left(A_{0}-A_{\mathrm{c}}\right) \times 100 \%(4)$

( $A_{0}$, the absorbance of blank group contain buffer solutions except sample; $A_{\mathrm{c}}$, the absorbance of complete inhibition group; $A_{\mathrm{s}}$, the absorbance of test group; $A_{\mathrm{b}}$, the absorbance of background group.)

\subsection{Computational modeling for AChE inhibitors}

2.8.1. Building of molecules using ChemBioDraw ultra and Spartan. 2D structures of all the isolated compounds 1 and 2 were drawn with the help of ChemBioDraw ultra version 14.0 and exported to window of Chem 3D ultra version 14.0. Energy of all the 3D structures was minimized through Spartan 14 V1.1.0 (Trial version) and saved in Sybyl Mol2 file (.Mol2) format.

2.8.2. Protein preparation. The X-ray crystal structure of the enzyme AChE in a complex with (-)-galanthamine (PDB code 1W6R, resolution: 2.05 $\mathrm{A}$ ) was obtained from the Protein Data Bank (http:/www.rcsb.org/pdb/hosme/home.do) and further prepared using the protein preparation wizard, which is accessible in Molegro virtual docker. ${ }^{15}$ In order to perform the docking calculations, water molecules were removed firstly. Then $\mathrm{H}$ atoms and charges were added to the crystal structure after sidechain repairment and termini treatment. In the next step, the complex crystal structure was energy minimized using the AMBER7 F99 force field with max minimize for 100 iterations.

2.8.3. Molecular docking studies. To evaluate the accuracy of our docking method, the crystal structure ${ }^{16}$ (PDB ID: 1W6R) with ligands in complex with human AChE was used for redocking tests. In order to avoid the bias from MVD software to the initial structure, the initial coordinates of ligands were generated by Spartan 14 software instead of that obtained from the crystal structures. The top 1 ranked binding structures obtained in our docking method are all having RMSD less than 2.5 $\AA$ as compared to the binding poses in crystal structures, indicating that our docking method is very reliable in reproducing the correct binding poses for AChE inhibitors. Docking of compounds 1 and 2 into the X-ray crystal structure of the enzyme AChE (PDB code 1W6R) was performed with Molegro virtual docker (Molegro) and exported with Discovery Studio Visualizer 2016 (Accelrys). All the modeling studies were carried out on a PC, Intel CoreTM i7-5820K CPU@3.30 GHz, RAM 32 GB operating under Windows 10 professional.

\subsection{SH-SY5Y neuroblastoma-based assay}

The SH-SY5Y neuroblastoma cells were maintained in DMEM, containing $10 \% \mathrm{FBS}, 100 \mathrm{U} \mathrm{mL}^{-1}$ penicillin and $100 \mu \mathrm{g} \mathrm{mL}$ streptomycin at $37{ }^{\circ} \mathrm{C}$ with $5 \% \mathrm{CO}_{2}$. Compounds 1 and 2 were dissolved in dimethyl sulfoxide (DMSO) to form different concentrations 0 to $100 \mu \mathrm{M} \mathrm{mL}{ }^{-1}$ (DMSO concentration $\leq$ $0.01 \%)$. Compounds 1, $2(25,50$ and $100 \mu \mathrm{M})$ and cells were incubated at $37{ }^{\circ} \mathrm{C}$ for $12 \mathrm{~h}$, after which $\mathrm{H}_{2} \mathrm{O}_{2}$ was added to a final concentration of $100 \mu \mathrm{M}$, and further incubated for $1.5 \mathrm{~h}$. Cell viability was detected colorimetrically by MTT test. ${ }^{17}$ The absorbance was measured at $490 \mathrm{~nm}$ via a microplate reader. The results of the experimental groups were normalized to the those of control group. Statistical analysis was carried out by analysis of variance (ANOVA) and SPSS statistical software (version 19 for Windows) $(* p<0.05)$.

\section{Results and discussion}

\subsection{Single-factor experiments and results}

3.1.1. The effect of ethanol concentration $\left(X_{1}\right)$. To assess the effect of $X_{1}$, the extraction was carried out in the presence of at $X_{1}$ of $40 \%, 50 \%, 60 \%, 70 \%$ and $80 \%$. Other conditions were performed in the presence of $X_{2}$ for $8 \mathrm{~min}, X_{3}$ of $20: 1 \mathrm{~mL} \mathrm{~g}^{-1}$ and $X_{4}$ at $400 \mathrm{~W}$. As shown in Fig. S5.1a, $\dagger$ when $X_{1}$ was increased from $40 \%$ to $60 \%$, the saponin content was significantly increased and reached a maximum when $X_{1}$ was $60 \%$. However, the saponin content decreased remarkably when the concentration of $X_{1}$ increased from $60 \%$ to $80 \%$. Thus, $X_{1}$ of $50-70 \%$ was used to extract TTSs in the optimized experiment.

3.1.2 The effect of extraction time $\left(X_{2}\right) \cdot X_{1}$ is a major determinant of the saponin content. The extraction was performed at the $X_{2}$ of 4, 6, 8, 10 and $12 \mathrm{~min}$ (other parameters: $\left.60 \%, 20: 1 \mathrm{~mL} \mathrm{~g}^{-1}, 400 \mathrm{~W}\right)$. As shown in Fig. S5.1b, $\dagger$ when $X_{2}$ was increased from 4 to $10 \mathrm{~min}$, the saponin content increased and reached the maximum at $10 \mathrm{~min}$. But it obvious decreased significantly when $X_{2}$ was increased to $12 \mathrm{~min}$. Therefore, $X_{2}$ at 8-12 min was used in the optimized experiments.

3.1.3. The effect of the ratio of liquid to raw material $\left(X_{3}\right)$. To the examine the effect of $X_{3}$, the extraction was conducted at $X_{3}$ of $10: 1,15: 1,20: 1,25: 1$ and $30: 1 \mathrm{~mL} \mathrm{~g}^{-1}$. Other extraction conditions were set as follows: the $X_{1}$ was $60 \%$, the $X_{2}$ was $8 \mathrm{~min}$, and the $X_{4}$ was $400 \mathrm{~W}$. As shown in Fig. S5.1c, $\dagger$ the saponin content increased obviously when the $X_{3}$ increased from $10: 1 \mathrm{~mL} \mathrm{~g}^{-1}$ to $25: 1 \mathrm{~mL} \mathrm{~g}^{-1}$. When $X_{3}$ was $25: 1 \mathrm{~mL} \mathrm{~g}^{-1}$, the saponin content reached its the maximum. But the saponin content decreased remarkably when $X_{3}$ was increased from $25: 1$ to $30: 1 \mathrm{~mL} \mathrm{~g}^{-1}$. Hence, the $X_{4}$ of $20: 1-30: 1 \mathrm{~mL} \mathrm{~g}^{-1}$ was selected as optimal for the BBD experiment.

3.1.4 The effect of microwave power $\left(X_{4}\right)$. The effect of $X_{4}$ $(200-600 \mathrm{~W})$ on the extraction of TTSs is shown in Fig. S5.1d $\dagger$ (other parameters were 60\%, $8 \mathrm{~min}$ and $20: 1 \mathrm{~mL} \mathrm{~g}^{-1}$ ). As 
Table 2 Analysis of variance for the response surface quadratic model for content of TTSs. $* p<0.05$ and $* * p<0.01$

\begin{tabular}{|c|c|c|c|c|c|c|}
\hline Source & Sum of squares & $\mathrm{df}$ & Mean square & $F$ value & $P$-value prob $>F$ & Significance \\
\hline Model & 236.71 & 14 & 16.91 & 37.78 & $<0.0001$ & $* *$ \\
\hline$X_{1}$ & 117.56 & 1 & 117.56 & 262.72 & $<0.0001$ & $* *$ \\
\hline$X_{3}$ & 12.48 & 1 & 12.48 & 27.90 & 0.0001 & $* *$ \\
\hline$X_{4}$ & 41.74 & 1 & 41.74 & 93.27 & $<0.0001$ & $* *$ \\
\hline$X_{1} X_{2}$ & 1.04 & 1 & 1.04 & 2.32 & 0.1496 & \\
\hline$X_{2} X_{3}$ & 1.82 & 1 & 1.82 & 4.07 & 0.0632 & \\
\hline$X_{2} X_{4}$ & 1.30 & 1 & 1.30 & 2.90 & 0.1104 & \\
\hline$X_{3} X_{4}$ & 0.20 & 1 & 0.20 & 0.45 & 0.5121 & \\
\hline$X_{1}^{2}$ & 2.54 & 1 & 2.54 & 5.68 & 0.0319 & $*$ \\
\hline$X_{2}{ }^{2}$ & 0.040 & 1 & 0.040 & 0.089 & 0.7694 & \\
\hline$X_{3}^{2}$ & 15.10 & 1 & 15.10 & 33.76 & $<0.0001$ & $* *$ \\
\hline Cor total & 242.98 & 28 & & & & \\
\hline
\end{tabular}

shown in Fig. S5.1d, $\uparrow$ the saponin content increased markedly when $X_{4}$ was increased from 200 to $500 \mathrm{~W}$ and it reached maximum at $500 \mathrm{~W}$. However, the results showed that it decreased from 500 to $600 \mathrm{~W}$. Therefore, the $X_{4}$ of $400-600 \mathrm{~W}$ was regarded as optimal for the BBD investigation.

\subsection{Optimization of the extraction parameters of MAE using BBD}

3.2.1 Model fitting and statistical analysis. According to the data from previous single-factor testing, the range and center point values of four independent parameters (the ethanol concentration, $X_{1}$, the extraction time, $X_{2}$, the ratio of liquid to raw material, $X_{3}$, and the microwave power, $X_{4}$ ) are shown in Table S2. $\uparrow$ To optimize the four independent variables using BBD, different experimental factors were tested and the experimental values of the response (content of TTSs) are shown in Table 1. Under the optimized technological conditions of the $X_{1}$ of $69 \%$, the $X_{2}$ of $12 \mathrm{~min}$, the $X_{3}$ of $26 \mathrm{~mL} \mathrm{~g}^{-1}$ and the $X_{4}$ of $528 \mathrm{~W}$, a maximum extraction of TTSs $\left(62.69 \mathrm{mg} \mathrm{g}^{-1}\right)$ was obtained by applying RSM. When the experimental results were subjected to multiple regression analysis, the test variables and the response variable were found to be relevant based on the single basic second-order polynomial formula (5):

$$
\begin{aligned}
Y= & 57.85+3.13 X_{1}+1.91 X_{2}+1.02 X_{3}+1.86 X_{4}+0.15 X_{1} X_{2} \\
& +0.18 X_{1} X_{3}+0.24 X_{1} X_{4}+0.68 X_{2} X_{3}+0.57 X_{2} X_{4}+0.22 X_{3} X_{4} \\
& +0.63 X_{1}{ }^{2}-0.079 X_{2}{ }^{2}-1.53 X_{3}{ }^{2}-0.51 X_{4}{ }^{2}
\end{aligned}
$$

$Y$ is the content of TTSs $\left(\mathrm{mg} \mathrm{g}^{-1}\right)$.

The results of data analysis using the BBD are presented in Table 2. The variance (ANOVA) analysis of the significance of the quadratic polynomial models ${ }^{4}$ of the content of TTSs showed that the coefficients of linear $\left(X_{1}, X_{2}, X_{3}\right.$ and $\left.X_{4}\right)$ and quadratic coefficients $\left(X_{3}^{2}\right)$ were highly significant $(P \leq 0.0001)$ with regard to the content of TTSs. In addition, statistical analysis of the quadratic coefficients $\left(X_{1}^{2}\right)$ with a small $p$-value $(P<0.05)$ revealed that they were significant. The $p$-value $(P<0.0001)$ polynomial model confirmed the suitability of this model to determine the content of TTSs. Moreover, the correlation coefficient of determination $\left(R^{2}\right)$ of 0.9742 indicated that the calculated model, the $R^{2}$-pred of 0.8535 and the $R^{2}$-adj of 0.9484 showed a close relationship between the experimental data and the theoretical values. At the same time, the lack of fit (0.0051) in the model exhibited significant difference and the small values of the coefficient of variation (C.V.) (1.18\%) suggested that the model was effective in analyzing the experimental data on the extraction of TTSs from RLMF by the MAE method.

3.2.2 Response of surface plot and contour plot analyses. The 3D response surfaces (Fig. 1) and their 2D contour plots (Fig. S2.1 $\dagger$ ) showed the relationship between responses (content of TTSs $\left.\left(Y ; \mathrm{mg} \mathrm{g}^{-1}\right)\right)$ and independent variables $\left(X_{1} ; \%, X_{2} ; \mathrm{min}\right.$, $X_{3} ; \mathrm{mL} \mathrm{g}^{-1}$ and $\left.X_{4} ; \mathrm{W}\right)$. The suitability of the polynomial model equation for the predictive response values could be assessed

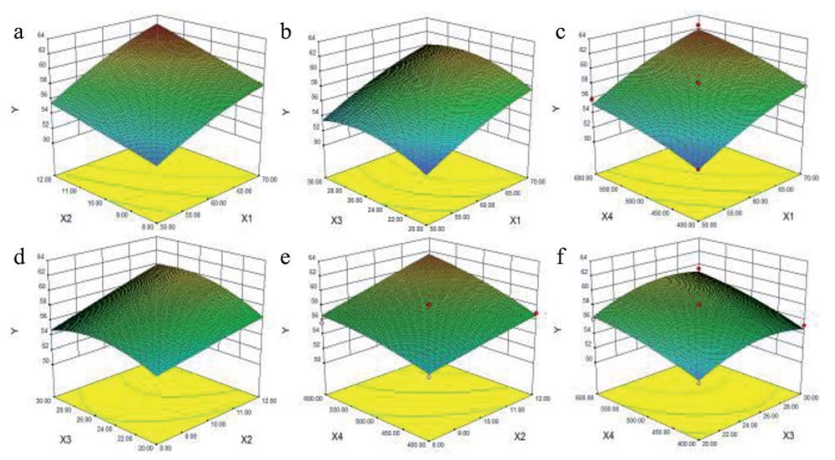

Fig. 1 Response surface plots displaying the interaction effects of $X_{1}$ and $X_{2}(\mathrm{a}), X_{1}$ and $X_{3}(\mathrm{~b}), X_{1}$ and $X_{4}(\mathrm{c}), X_{2}$ and $X_{3}(\mathrm{~d}), X_{2}$ and $X_{4}(\mathrm{e}), X_{3}$ and $X_{4}$ (f) on the saponin content yield of Rosa laevigata Michx. fruits. $X_{1}$ : ethanol concentration; $X_{2}$ : extraction time; $X_{3}$ : ratio of liquid to raw material; $X_{4}$ : microwave power. 
under the optimal extraction conditions. Moreover, the shapes of these plots obtained by keeping two factors constant at zero while changing the other two factors, were used to determine whether mutual interactions between two variables had significant effect ${ }^{7}$ on the responses.

Fig. 1a and S2.1a $\uparrow$ shows the effects of $X_{1}$ and $X_{2}$ on the content of TTSs calculated using eqn (5) at a fixed $X_{3}(25: 1 \mathrm{~mL}$ $\left.\mathrm{g}^{-1}\right)$ and $X_{4}(500 \mathrm{~W})$. From the two figures, the maximum content of TTSs was obtained when $X_{1}$ and $X_{2}$ were $70 \%$ and $12 \mathrm{~min}$, respectively.

The 3-D plot shown in Fig. $1 \mathrm{~b}$ and the contour plot shown in Fig. S2.1b, $\dagger$ for two fixed variables $X_{2}$ of $10 \mathrm{~min}$ and $X_{4}$ of $500 \mathrm{~W}$, showed that the content of TTSs increased as the ratio of liquid to raw material increased from $20: 1$ to $26: 1 \mathrm{~mL} \mathrm{~g}^{-1}$, but beyond $26: 1 \mathrm{~mL} \mathrm{~g}^{-1}$, the content of TTSs increased parallel to the concentration of ethanol.

As shown in Fig. 1c and S2.1c, $\dagger$ it was evident that the content of TTSs increased rapidly as the $X_{1}$ increased from $50 \%$ to $70 \%$, but the increase was slowly as the value of $X_{4}$ increased.

The 3-D plot and the contour plot for the independent factors $X_{2}$ and $X_{3}$ when both $X_{1}$ and $X_{4}$ were zero are shown in Fig. 1 d. A significant increase in the content of TTSs was observed when the extraction duration was increased from 8 to $12 \mathrm{~min}$, and the content of TTSs increased with an increase in the $X_{3}$ from $20: 1$ to $26: 1 \mathrm{~mL} \mathrm{~g}^{-1}$, but decreased beyond $26: 1 \mathrm{~mL} \mathrm{~g}^{-1}$.

From the 3-D plot in shown in Fig. 1e and the contour plot shown in Fig. S2.1e, $\uparrow$ it can be concluded that the content of TTSs increased rapidly with an increase in $X_{2}$ from 8 to $12 \mathrm{~min}$, and an increase in the $X_{4}$ ranging from 400 to $600 \mathrm{~W}$.

Fig. If and S2.1f $\dagger$ show the 3-D response surface plot and the contour plot for variations in the $X_{3}$ and $X_{4}$. The content of TTSs

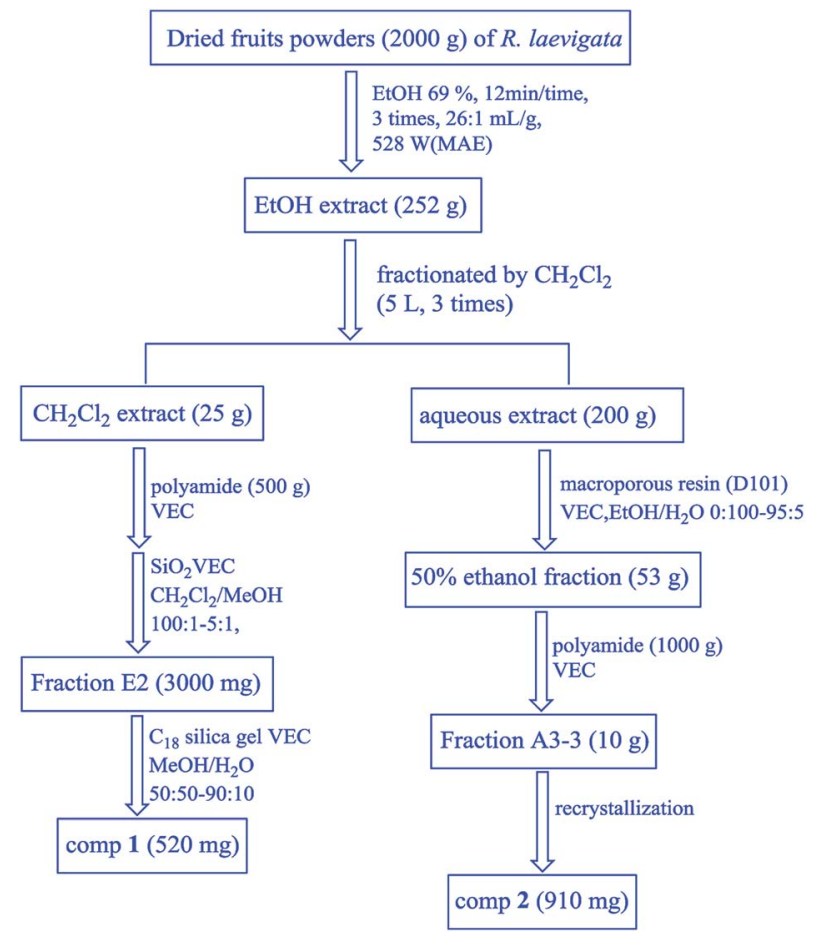

Fig. 2 The scheme for the isolation of compounds 1 and 2 from the fruits of $R$. laevigata. increased linearly with $X_{4}$ of 400-500 W whereas it decreased with the increasing ratio of liquid to raw material from $26: 1$ to $30: 1 \mathrm{~mL} \mathrm{~g}^{-1}$. The maximum content of TTSs was achieved at ethanol concentration of $69 \%$, extraction time of $12 \mathrm{~min}$; a ratio of liquid to raw material of $26: 1 \mathrm{~mL} \mathrm{~g}^{-1}$ and microwave power of $528 \mathrm{~W}$.

3.2.3 Validation of the predictive model. To validate the suitability of the predictive model, a verification experiment was conducted three times under the optimal following conditions by the RSM: a $X_{1}$ of $69 \% ; X_{2}$ of $12 \mathrm{~min} ; X_{3}$ of $26: 1 \mathrm{~mL} \mathrm{~g}^{-1} ; X_{4}$ of $528 \mathrm{~W}$. An experimental value of $62.48 \pm 0.25 \mathrm{mg} \mathrm{g}^{-1}$ obtained from the verification experiments was consistent with the predicted value of $62.69 \mathrm{mg} \mathrm{g}^{-1}$ (Table $\mathrm{S} 3 \dagger$ ). Therefore, the predictive model and its formula (5) were confirmed to be suitable for optimizing the process of TTSs extraction from Rosa laevigata Michx. fruit (RLMF) using the microwave-assisted extraction (MAE) technique.

\subsection{Determination of compounds}

Compound 1 was characterized by ESIMS, ${ }^{1} \mathrm{H}$ and ${ }^{13} \mathrm{C}$ NMR spectroscopies. The molecular formula $\mathrm{C}_{30} \mathrm{H}_{48} \mathrm{O}_{6}$ was inferred from the ESI-MS spectrum: $m / z 527[\mathrm{M}+\mathrm{Na}]^{+}$and $m / z 1031[2 \mathrm{M}+$ $\mathrm{Na}]^{+}$, indicating that it had a MW of 504 dalton and seven degrees of double-bond equivalence. The ${ }^{1} \mathrm{H}$ NMR spectrum of 1 showed six tertiary methyl groups at $\delta_{\mathrm{H}} \mathrm{ppm}: 1.62(3 \mathrm{H}, \mathrm{s}), 1.48(3 \mathrm{H}, \mathrm{s}), 1.10$ $(3 \mathrm{H}, \mathrm{s}), 1.09(3 \mathrm{H}, \mathrm{d}, J=6.8 \mathrm{~Hz}), 1.07(3 \mathrm{H}, \mathrm{s})$, and $1.04(3 \mathrm{H}, \mathrm{s})$, a olefinic proton at $\delta_{\mathrm{H}} 5.55(1 \mathrm{H}, \mathrm{brs})$, two oxygen-bearing methylene protons at $\delta_{\mathrm{H}} 4.17(1 \mathrm{H}, \mathrm{d}, J=10.8 \mathrm{~Hz})$ and $4.15(1 \mathrm{H}, \mathrm{d}, J=10.8$ $\mathrm{Hz}$ ), and two oxygen-bearing methine protons at $\delta_{\mathrm{H}} 4.23(1 \mathrm{H}, \mathrm{dt}, J$ $=9.6,4.2 \mathrm{~Hz})$ and $3.69(1 \mathrm{H}, \mathrm{d}, J=9.6 \mathrm{~Hz})$. The ${ }^{13} \mathrm{C}$ NMR spectrum exhibited 30 carbon resonances (Table S1 $\dagger$ ), and further information of compound 1 was obtained from the DEPT-135 experiment, including functional group signals of four carbons bearing oxygen $\delta_{\mathrm{C}}$ : $66.5\left(23-\mathrm{CH}_{2}-\mathrm{O}\right), 68.8$ (2-CH-O), 72.6 (19-C-O), and 78.3 (3-CH$\mathrm{O})$, a double bond group $\delta_{\mathrm{C}}: 139.9(13-\mathrm{C}=\mathrm{CH})$ and $127.9(12-\mathrm{CH}=$ $\mathrm{C})$ and a carbonyl group $180.6(28-\mathrm{C}=\mathrm{O})$. Furthermore, there were six methyls at $\delta_{\mathrm{C}} 14.3\left(\mathrm{CH}_{3}-24\right), 16.7\left(\mathrm{CH}_{3}-25\right), 17.2\left(\mathrm{CH}_{3}-26\right), 24.6$ $\left(\mathrm{CH}_{3}-27\right), 27.0\left(\mathrm{CH}_{3}-29\right)$, and $17.3\left(\mathrm{CH}_{3}-30\right)$, eight methylenes $\delta_{\mathrm{C}}$ $47.8\left(\mathrm{CH}_{2}-1\right), 18.6\left(\mathrm{CH}_{2}-6\right), 33.1\left(\mathrm{CH}_{2}-7\right), 24.1\left(\mathrm{CH}_{2}-11\right), 29.2\left(\mathrm{CH}_{2}-\right.$ 15), $26.3\left(\mathrm{CH}_{2}-16\right), 26.9\left(\mathrm{CH}_{2}-21\right)$, and $38.3\left(\mathrm{CH}_{2}-22\right)$, four methines $\delta_{\mathrm{C}}: 47.9$ (CH-5), 47.8 (CH-9), 54.5 (CH-18), and 42.3 (CH-20), and five quaternary carbons $\delta_{\mathrm{C}}: 42.1(\mathrm{C}-4), 40.4(\mathrm{C}-8), 38.3$ (C-10), 42.1 (C-14), and 48.3 (C-17), which suggested that compound 1 is $2 \alpha, 3 \beta, 19 \alpha, 23$-tetrahydroxyurs-12-en-28-oic acid. ${ }^{6}$

Compound 2 was also characterised by ESIMS, ${ }^{1} \mathrm{H}$ and ${ }^{13} \mathrm{C}$ NMR spectroscopies. The molecular formula of compound 2 $\mathrm{C}_{36} \mathrm{H}_{58} \mathrm{O}_{11}$ was inferred from the ESI-MS spectrum: $[\mathrm{M}+\mathrm{Na}]^{+}$ peak at $m / z 689$ (the major fragment ion) and $[2 \mathrm{M}+\mathrm{Na}]^{+}$peak at $\mathrm{m} / \mathrm{z} 1355$, demonstrating that it had a MW of 666 and eight degrees of double-bond equivalence. A comparison of NMR data (Table S1 $\dagger$ ) suggested that compounds 1 and 2 had the same triterpenoid skeleton, except for the presence of one additional $\mathrm{C}_{6} \mathrm{H}_{10} \mathrm{O}_{5}$ sugar unit in compound 2, and this was confirmed from its molecular formula. Furthermore, the glycosidic site was determined from the upfield shift of the carbonyl carbon signal (C-28) in the ${ }^{13} \mathrm{C}$ NMR from $180.5(\mathrm{C}=\mathrm{O})$ to $178.5(\mathrm{C}=\mathrm{O})$, 
indicating that C-28 was assigned to the linkage site between the triterpenoid skeleton and the sugar. ${ }^{6}$

To further determine the structure of the sugar, compound 2 was analyzed by acid hydrolysis followed by PMP derivatization prior to HPLC, and comparison with an standard sample by HPLC analysis with UV detector. The HPLC profile (Fig. S3.1†) showed that the PMP derivative of 2 had similar retention properties with the derivative of $\beta$-D-glucose. Hence, compound 2 was identified as $2 \alpha, 3 \beta, 19 \alpha, 23$-tetrahydroxyurs-12-en-28-oic acid-28- $O$ - $\beta$-D-glucopyrannoside.

\subsection{Method validation}

To analyze the MAE method, several factors such as linearity, reproducibility, recovery, precision and stability were examined using the optimized factors. Compounds $\mathbf{1}$ and 2 were examined by comparison with the chromatograms and retention times of the standard samples. Fig. 1 shows that the retention time of 1 and 2 purified from RLMF was consistent with the that of standard 1 and 2 ( $\left.t_{\mathrm{R} 1} 7.0 \mathrm{~min}, t_{\mathrm{R} 2} 32.0 \mathrm{~min}\right)$.

\subsection{Sample analysis}

Rosa laevigata Michx. fruits (RLMF) were collected from Nanning, Guangxi province, P. R. China, in October 2016. Compounds 1 and 2 were extracted with optimized MAE conditions and characterized using the HPLC method. The quantities of the extracts were calculated by determining the peak area. The result indicated that their quantities in the fruit were 5.36 and $10.37 \mathrm{mg} \mathrm{g}^{-1}$, respectively.

\subsection{AChE inhibitory effects}

Our preliminary in vitro screening study indicated that the $69 \%$ EtOH extract from the fruits of $R$. laevigata showed potent AChE inhibitory activity, with $\mathrm{IC}_{50}$ value of $36.33 \mu \mathrm{g} \mathrm{mL} \mathrm{m}^{-1}$, in which galanthamine, a well-known natural AChE inhibitor, was used as a positive control with an $\mathrm{IC}_{50}$ value of $36.30 \mu \mathrm{g} \mathrm{mL}{ }^{-1}$ which is consistent with that reported in our previous study. ${ }^{13}$ Furthermore, its $\mathrm{CH}_{2} \mathrm{Cl}_{2}$-soluble extract fraction showed stronger AChE inhibitory activity, with an $\mathrm{IC}_{50}$ value of $26.371 \mu \mathrm{g} \mathrm{mL}^{-1}$. Compound 1, the main constituent of the $\mathrm{CH}_{2} \mathrm{Cl}_{2}$-soluble active fraction, showed potent $\mathrm{AChE}$ inhibitory activity with an $\mathrm{IC}_{50}$ value of $29.22 \mu \mathrm{g} \mathrm{mL} \mathrm{mL}^{-1}$, which was stronger compared to compound 2 ( $\mathrm{IC}_{50}$ value of $45.47 \mu \mathrm{g} \mathrm{mL}^{-1}$ ) from the aqueous active fraction. At a concentration of $2-200 \mu \mathrm{g} \mathrm{mL}{ }^{-1}$ for both compounds, different active fractions, exhibited varying degrees of inhibition (Fig. 3). Compounds 1 and 2 showed significant AChE inhibitory activity, of $92 \%$ and $89 \%$, respectively. Furthermore, the results showed that a dose-response effect was observed in each concentration curve of different samples.

\subsection{Interactions of bioactive compounds with AChE protein}

Interactions between compounds $\mathbf{1}$ and $\mathbf{2}$ with AChE protein were carried out via molecular modeling (Fig. 4). The experiments showed that the $23-\mathrm{OH}$ of $\mathbf{1}$ and the catalytic residues (PHE 288 and ARG 289) were in close proximity, and exhibited hydrogen bonding interactions (distance 2.29 and $2.20 \AA$ ). The

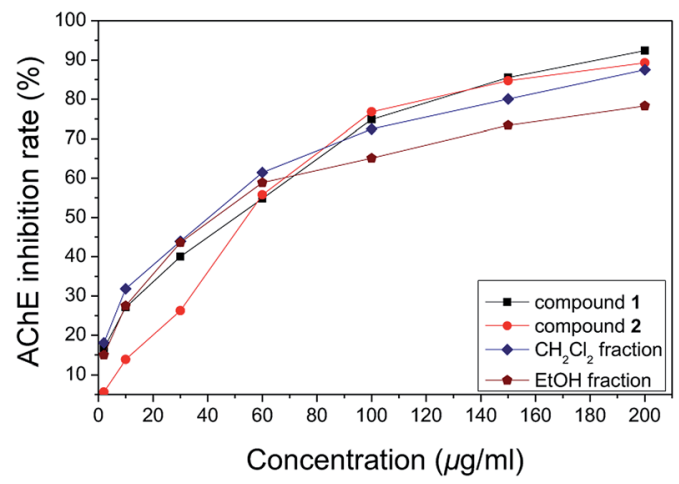

Fig. 3 The curve plot showing a dose AChE inhibition rate in each concentration curve of different samples.

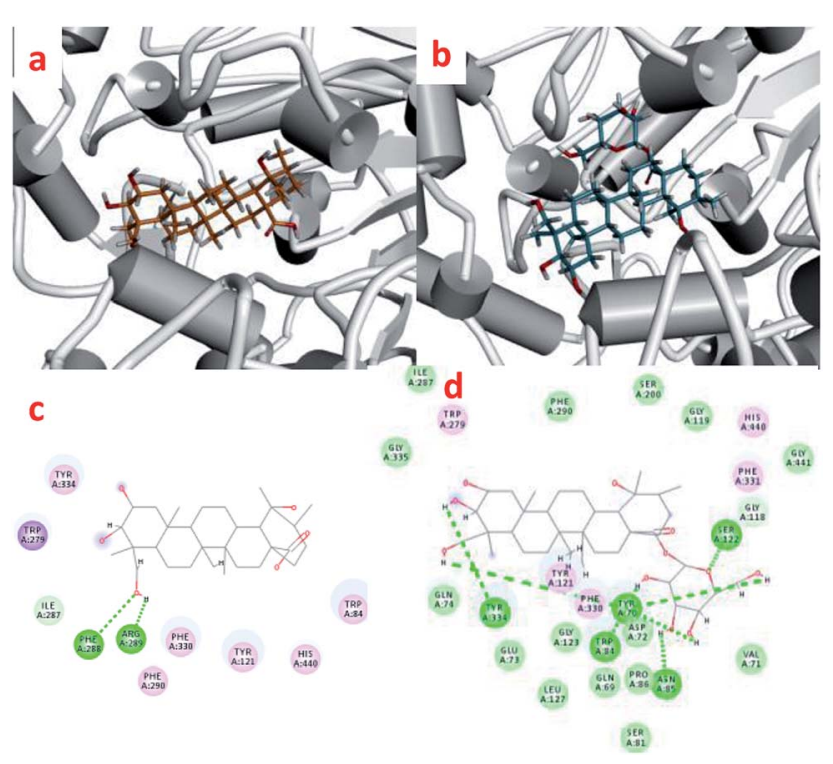

Fig. 4 The enzyme-ligand binding interactions of compounds 1 and 2 .

$\mathrm{H}$-bond interactions were situated at positions of the Try 70, Tyr 334 and 3,23-OH (distance 2.35 and $2.66 \AA$ ) as well as those of Try 70, Trp 84, Asn 85, Ser 122 and glycosyl of 2 (distance 1.69, 2.48, 2.05, 1.60 and $1.52 \AA$ ). Compounds 1 and 2 were found in the aromatic pocket formed by Tyr334, Phe330 and Trp279. Moreover, PHE290, His440, and ILE287 were found to essential active residues.

\subsection{Protective effect of SH-SY5Y neuroblastoma cells}

According to previous studies, the SH-SY5Y cell line is an efficient model for investigating the mechanisms of neurodegeneration induced by $\mathrm{H}_{2} \mathrm{O}_{2} \cdot{ }^{17}$ The protective effects of compounds 1 and 2 were examined via the MTT test. As shown in Fig. 5, cell viability following exposure to $\mathrm{H}_{2} \mathrm{O}_{2}(100 \mu \mathrm{M})$ was $56.64 \pm 37.65 \%$. Cell viabilities at $25 \mu \mathrm{M}, 50 \mu \mathrm{M}$ and $100 \mu \mathrm{M}$ of compound 1 or 2 were $60.53 \pm 8.34 \%, 56.89 \pm 9.37 \%, 63.15 \pm$ $5.33 \%$ and $58.83 \pm 8.95 \%, 59.93 \pm 5.21 \%, 61.53 \pm 1.52 \%$, respectively. The results of the cell growth are shown in Fig. 6. In addition, the phase contrast microscope was used to analyze the morphological features of the cells. We found that treatment of 


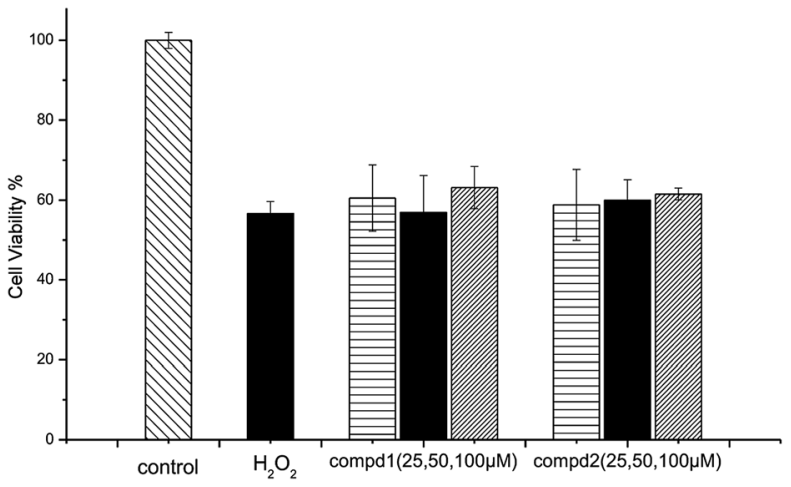

Fig. 5 Protective effects of compounds 1 and 2 against $\mathrm{H}_{2} \mathrm{O}_{2}$-induced SH-SY5Y cell death.

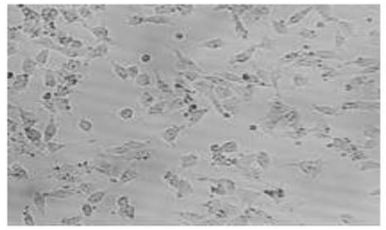

Control

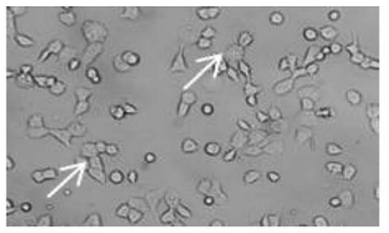

$\mathrm{H}_{2} \mathrm{O}_{2}+$ Compound 1

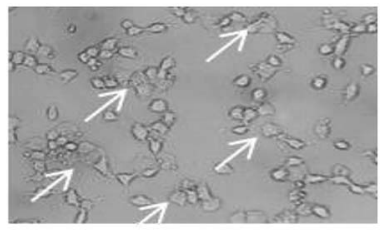

$\mathrm{H}_{2} \mathrm{O}_{2}$

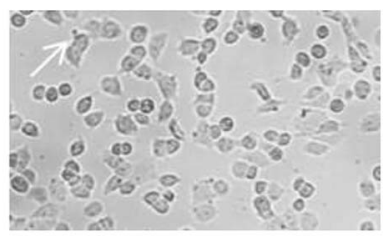

$\mathrm{H}_{2} \mathrm{O}_{2}+$ Compound 2
Fig. 6 Meliorative effects of compounds 1 and 2 with $\mathrm{H}_{2} \mathrm{O}_{2}$ induced morphological changes in $\mathrm{SH}-\mathrm{SY} 5 \mathrm{Y}$ cells.

cells with $\mathrm{H}_{2} \mathrm{O}_{2}(100 \mathrm{M})$ for $1.5 \mathrm{~h}$ led to cells loss, synapse injury, and shrinkage compared to the control group. Interestingly, pretreatment with different concentrations of compound $\mathbf{1}$ or $\mathbf{2}$ for $12 \mathrm{~h}$ before adding $\mathrm{H}_{2} \mathrm{O}_{2}$ significantly ameliorated the cell injury. It can be deduced that cell growth is in accordance with the cell viability results. Thus, compounds 1 and 2 showed protective effects against $\mathrm{H}_{2} \mathrm{O}_{2}$-induced SH-SY5Y neuroblastoma cell death.

\section{Conclusions}

In this study, two major polyhydroxy triterpenoids (2 $\alpha, 3 \beta, 19 \alpha, 23$-tetrahydroxyurs-12-en-28-oic acid and $2 \alpha, 3 \beta, 19 \alpha, 23$-tetrahydroxyurs-12-en-28-oic acid-28-O- $\beta$-D-glucopyrannoside) were purified from triterpenoids (TTs) of Rosa laevigata Michx. fruit using microwave-assisted extraction (MAE) technology coupled with multi vacuum extraction columns (VEC) method. Based on the single-parameter experiments, response surface optimization (RSM), which reduces the extraction duration, amount of solvent and raw material needed, and was applied to optimize the four experimental variables (ethanol concentration, 69\%; extraction time, $12 \mathrm{~min}$; ratio of liquid to raw material, $26: 1 \mathrm{~mL} \mathrm{~g}^{-1}$; and microwave power, $528 \mathrm{~W}$ ). Under these optimum conditions, the experimental content of TTSs was in accordance with the predicted value of $62.69 \mathrm{mg} \mathrm{g}^{-1}$. Further analysis of the purified compounds 1 and 2 revealed that their quantities in the fruit were 5.36 and $10.37 \mathrm{mg} \mathrm{g}^{-1}$, respectively. To the best of our knowledge, this is the first report on enrichment of TTSs, the principal constituents of $R$. laevigata using rapid extraction techniques. In vitro assays demonstrated that the acetylcholinesterase inhibitory activity of compound $\mathbf{1}$ (with an $\mathrm{IC}_{50}$ value of $29.22 \mu \mathrm{g} \mathrm{mL}^{-1}$ ) was stronger than compound 2 (with an $\mathrm{IC}_{50}$ value of $\left.45.47 \mu \mathrm{g} \mathrm{mL}^{-1}\right)$. At a concentration of $2-200 \mu \mathrm{g} \mathrm{mL} \mathrm{L}^{-1}$, a dose-response effect was observed in the concentration curves of each isolate. Docking studies were performed which demonstrated to the presence of interaction between compounds $\mathbf{1}$ and $\mathbf{2}$ with AChE protein. Both compounds $\mathbf{1}$ and 2 (at the concentration of $25-100 \mu \mathrm{M}$ ) exhibited significant protective effects against $\mathrm{H}_{2} \mathrm{O}_{2}$-induced cell death of SH-SY5Y neuroblastoma cells. Collectively, the two active polyhydroxy triterpenoids $\mathbf{1}$ and $\mathbf{2}$ were characterized and found to possess acetylcholinesterase inhibitory efforts and neuroprotection functions during nontoxic condition. These findings imply that the two compounds are potential bioactive agents that can be used to develop drugs for $\mathrm{AD}$ treatment.

\section{Conflicts of interest}

There are no conflicts to declare.

\section{Acknowledgements}

The authors gratefully thank National Natural Science Foundation of China (81703377), Natural Science Foundation from Liaoning province of China (20170540723) and the Key R \& D and Technology Transfer Program from Shenyang of Liaoning province of China (Y17-0-001).

\section{References}

1 Z. Sui, C. Qi, Y. Huang, S. Ma, X. Wang, G. Le and Z. Sun, Aqueous extracts from asparagus stems prevent memory impairments in scopolamine-treated mice, Food Funct., 2017, 8, 1460-1467.

2 A. Ciaramella, F. Salani, F. Bizzoni, M. D. Orfei, C. Caltagirone, G. Spalletta and P. Bossù, Myeloid dendritic cells are decreased in peripheral blood of Alzheimer's disease patients in association with disease progression and severity of depressive symptoms, J. Neuroinflammation, 2016, 13, 18.

3 S. Pacifico, S. Piccolella, A. Lettieri, P. Nocera, F. Bollino and M. Catauro, A metabolic profiling approach to an Italian sage leaf extract (SoA541) defines its antioxidant and antiacetylcholinesterase properties, J. Funct. Foods, 2017, 29, 1-9.

4 J. Q. Yuan, X. Z. Yang, J. H. Miao, C. P. Tang, C. Q. Ke, J. B. Zhang, X. J. Ma and Y. Ye, New Triterpene Glucosides from the Roots of Rosa laevigata Michx, Molecules, 2008, 13, 2229-2237. 
5 Y. T. Liu, B. N. Lu, L. N. Xu, L. H. Yin, X. N. Wang, J. Y. Peng and K. X. Liu, The antioxidant activity and hypolipidemic activity of the total flavonoids from the fruit of Rosa laevigata michx, Natural Science, 2010, 2, 175-183.

6 X. G. Liu, W. C. Zhang, M. Jin, Z. Y. Wu, X. K. Mu and P. Y. Gao, Isolation and identification of triterpenes of fruit of Rosa laevigata michx, J. Shenyang Pharm. Univ., 2013, 11, 851-857.

7 H. Yan, B. X. Han, Q. Y. Wu, M. Z. Jiang and Z. Z. Gui, Rapid Detection of Rosa laevigata polysaccharide content by nearInfrared spectroscopy, Spectrochim. Acta, Part A, 2011, 79(1), 179-184.

8 Y. Zhuang, Y. Z. He, B. Wang, Q. S. Chen, X. L. Zhou and J. Q. Yuan, Triterpenes from Rosa Laevigata Michx. and its activity, J. Chin. Med. Mater., 2012, 35, 162-164.

9 T. Wu, J. Yan, R. Liu, M. F. Marcone, H. A. Aisa and R. Tsao, Optimization of microwave assisted extraction of phenolics from potato and its downstream waste using orthogonal array design, Food Chem., 2012, 133, 1292-1298.

$10 \mathrm{~W}$. Routray and V. Orsat, Microwave-Assisted Extraction of Flavonoids: A Review, Food Bioprocess Technol., 2012, 5, 409-424.

11 J. G. Gujara, S. J. Wagha and V. G. Gaikar, Experimental and modeling studies on microwave-assisted extraction of thymol from seeds of Trachyspermum ammi (TA), Sep. Purif. Technol., 2010, 70, 257-264.

12 H. Zhang, J. Birch, C. Xie, H. Yang, G. Dias, L. Kong and A. E. Bekhit, Optimization of extraction parameters of antioxidant activity of extracts from New Zealand and
Chinese Asparagus officinalis L root cultivars, Ind. Crops Prod., 2018, 119, 191-200.

13 P. Y. Gao, M. Wang, X. G. Liu, Y. X. Gao, J. L. Li, Z. X. Zhang, H. W. Lin and S. J. Song, Triterpenes from the fruits of Rosa laevigata with acetylcholinesterase and $\mathrm{A} \beta$-aggregation inhibitory activities, RSC Adv., 2016, 6, 2431-2435.

14 K. Rhee, d. M. M. Van, K. Ingkaninan and R. Verpoorte, Screening for acetylcholinesterase inhibitors from Amaryllidaceae using silica gel thin-layer chromatography in combination with bioactivity staining, J. Chromatogr. A, 2001, 915, 217-223.

15 G. Lotfy, M. M. Said, E. S. El Ashry, E. S. El Tamany, A. AlDhfyan, Y. M. Abdel Aziz and A. Barakat, Synthesis of new spirooxindole-pyrrolothiazole derivatives: Anti-cancer activity and molecular docking, Bioorg. Med. Chem., 2017, 25(4), 1514-1523.

16 H. M. Greenblatt, C. Guillou, D. Guénard, A. Argaman, S. Botti, B. Badet, C. Thal, I. Silman and J. L. Sussman, The Complex of a Bivalent Derivative of Galanthamine with Torpedo Acetylcholinesterase Displays Drastic Deformation of the Active-Site Gorge: Implications for Structure-Based Drug Design, J. Am. Chem. Soc., 2004, 126, 15405-15411.

17 X. L. Hu, Y. X. Niu, Q. Zhang, X. Tian, L. Y. Gao, L. P. Guo, W. H. Meng and Q. C. Zhao, Neuroprotective effects of Kukoamine B against hydrogen peroxide-induced apoptosis and potential mechanisms in SH-SY5Y cells, Environ. Toxicol. Pharmacol., 2015, 40, 230-240. 